\title{
RECENSIÓN AL LIBRO: \\ "ARMONIZACIÓN EUROPEA DE LAS PRÁCTICAS \\ COMERCIALES DESLEALES: NUEVAS MEDIDAS \\ PARA EQUILIBRAR LA NEGOCIACIÓN EN LA \\ CADENA ALIMENTARIA"
}

\author{
María del Mar Bardera Baldrich \\ Universidad de Almería \\ E-mail: $\underline{\text { mdmbardera@yahoo.es }}$
}

En esta monografía, realizada por la Dra. María José Cazorla, que lleva por título Armonización europea de las prácticas comerciales desleales: nuevas medidas para equilibrar la negociación en la cadena alimentaria, nos muestra los instrumentos y herramientas con las que se pretende afrontar las asimetrías que durante años, vienen existiendo en la contratación dentro de la cadena alimentaria, en el marco europeo con la Directiva (UE) 2019/633 del Parlamento Europeo y del Consejo, de 17 de abril de 2019, relativa a las prácticas comerciales desleales en las relaciones entre empresas en la cadena de suministro agrícola y alimentario; y a nivel nacional con el Proyecto de Ley por la que se modifica la Ley 12/2013, de 2 de agosto, de medidas para mejorar el funcionamiento de la cadena alimentaria, que viene precedido por el Real Decreto-ley 5/2020, de 25 de febrero, por el que se adoptan determinadas medidas urgentes en materia de agricultura y alimentación.

Y lo hace en el marco de los objetivos establecidos por la Agenda 2030, donde se persigue la igualdad entre las personas, proteger el planeta y asegurar la prosperidad, porque en la nueva PAC 2021-2027, la Comisión exige a cada Estado miembro que elabore un plan estratégico donde como defiende la autora, la defensa por la competitividad de los productores ocupará un pilar determinante.

La profesora Cazorla González analiza en 5 capítulos la normativa que, en plena situación de pandemia, se ha publicado en beneficio del productor para fortalecer un sector vulnerable en la comercialización del producto tanto en la compraventa como en el contrato de suministro.

Comienza por la familia agraria como sujeto a proteger en la cadena alimentaria, donde es la comunidad de bienes la que afronta las obligaciones que tiene el agricultor y sus responsabilidades derivadas no solo de la negociación o del acuerdo, sino también del marco legal. A este último se refiere la monografía para hacer entender al lector que la vulnerabilidad del productor a veces la arrastra de la cantidad desproporcional de obligaciones y responsabilidad, que las normas le asignan al agricultor, sin hacer un reparto en corresponsabilidad con otros agentes de la cadena.

A continuación, en el capitulo segundo, se habla sobre la vulnerabilidad del agricultor bajo la regulación de la Directiva (UE) 2019/633, donde se especifica el contexto 
donde se producen las conductas comerciales desleales, señalando que se practican por los agentes de la cadena alimentaria de mayor tamaño frente a los agentes que tienen menor poder de negociación, que viene directamente relacionada, bien por tamaño en lo que al numero de productores que integra la entidad asociativa agraria o bien por la cuantía de su facturación de la misma, así como los límites respecto de los sujetos que, bajo esta Directiva van a quedar protegidos, ya que cuando establece el límite en función del volumen de negocio anual, determina que no haya posibilidad de conceder protección a quienes no sean vulnerables.

A continuación entra en el siguiente capitulo en la contratación alimentaria, analizando las condiciones generales de la contratación, los contratos tipo homologados y publicados por el ministerio, para pasar en el capítulo IV a valorar el código de buenas prácticas mercantiles y las normas de defensa de la competencia bajo la interpretación de la Directiva 633, finalizando en el ultimo capítulo con propuestas de mejora de la cadena alimentaria, a través del Proyecto de Ley de mejora de la cadena alimentaria y el Real Decreto 8/2020, actualmente publicado como Ley 8/2020, de 16 de diciembre, por la que se adoptan determinadas medidas urgentes en materia de agricultura y alimentación.

Finalizamos, animando al lector a leer este libro, que consideramos imprescindible para entender la normativa incesante que en 2020 ha venido afectando a la contratación dentro de la cadena alimentaria, desde un punto doctrinal y para el ámbito profesional, en la aplicación de todas estas normas a la hora de redactar el contrato. 